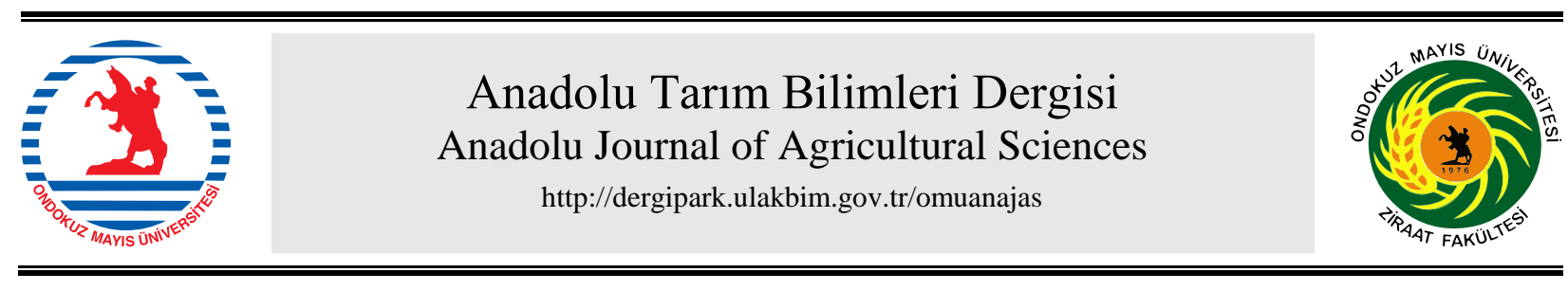

Araştırma/Research

Anadolu Tarım Bilim. Derg./Anadolu J Agr Sci, 31 (2016) ISSN: 1308-8750 (Print) 1308-8769 (Online) doi: 10.7161/omuanajas.260985

\title{
Arazi kalite değerlendirme çalışmalarında parametrik yöntem ve deneysel tasarım
}

\author{
Yasemin Şişman $^{a}$, Orhan Dengiz ${ }^{b}$, Aziz Şişman $^{a}$, İnci Demirağ Turan ${ }^{c *}$ \\ ${ }^{a}$ Ondokuz Mayıs Üniversitesi, Mühendislik Fakültesi, Harita Mühendisliği Bölümü, Samsun, ${ }^{b}$ Ondokuz Mayls Üniversitesi, Ziraat Fakültesi, \\ Toprak Bilimi ve Bitki Besleme Bölümü, Samsun, ${ }^{c}$ Ondokuz Mayıs Üniversitesi, Fen Edebiyat Fakültesi, Coğrafya Bölümü, Samsun \\ Sorumlu yazar/corresponding author:dmrginci@gmail.com
}

Geliş/Received 07/12/2015 Kabul/Accepted 04/04/2016

\begin{abstract}
ÖZET
Birçok faktörün sonuç (bağımlı) değişkeni üzerindeki ana ve etkileşimli etkileri deneysel tasarım yöntemleri ile irdelenebilir, bu yöntemlerden birisi tam faktöriyel deney tasarımdır. Bu çalışmanın amac1, küresel yer belirleme aleti kullanılarak belirlenen noktalardan 889 adet 0-20 cm derinlikten alınan toprak örneklerinin, fiziksel ve kimyasal özelliklerine dayanarak Samsun ili tarım arazilerinin kalite durumların parametrik yöntemle belirlenmesi ve bu yöntem içerisinde ele alınan 4 deneysel faktörün tam faktöriyel deney tasarım yöntemi ile arazi kalite indeksi üzerine olan etkilerini incelemektir. Samsun ili tarım arazilerinin arazi kalite indeksi durumlarını belirleme amacıyla yapılan çalışmanın verilerinde; toprak derinliği, eğim, bünye, toprak reaksiyonu, elektriksel iletkenlik ve organik madde deneysel faktörler olarak belirlenmiştir. Deneysel faktörlerin ve seviyelerinin öneminin belirlenmesi için deney sonuçları Minitab16 istatistik programı ile değerlendirilmiş ve Samsun Bölgesi arazi kalite indeksi (AKİ) için kullanılacak bir regresyon eşitliği önerilmiştir. Ayrıca bu çalışma sonucunda, toplam 32 deney kullanılarak 889 noktalı Samsun AKI çalışması sonuçlarının \%98.96 oranında temsil edilebilirliği görülmüştür.
\end{abstract}

Parametric approach in land quality assessment studies and experimental design

\section{ABSTRACT}

The main and interactive effect on response variable of multiple factors can be investigated using experimental design methods, one of which is full factorial design. The aim of this study is to determine land quality index of agricultural fields in Samsun province using parametric approach according to some physical and chemical properties of 889 soil samples from $0-20 \mathrm{~cm}$ soil depth using global positioning system and to analyze effects of experimental factors on land quality index (LQI) using $2^{4}$ factorial designs. Soil depth, slope, texture, soil reaction, electrical conductivity and organic matter were determined as experimental factors. In order to determine experimental factor and their significance Minitab16 statistical software was used and a recreation model was suggested for Samsun region. In addition to that, in the result of this study it was represented as about $98.96 \%$ for the results of LQI of Samsun selected 889 points using 32 samples.

Anahtar Sözcükler: Arazi kalite indeksi Deney tasarımı Parametrik yaklaşım Tam faktöriyel deney tasarımı

\section{Giriş}

Önemli doğal kaynaklar içerisinde yer alan toprak ve arazi kaynaklarının, sürdürülebilir kullanımlarının sağlanması için, bu kaynaklar hakkında doğru, yeterli, hızlı veri ve bilgilerin üretilmesine önemle ihtiyaç duyulmaktadır. Bu nedenle günümüz teknolojilerinden yararlanarak akılcı analizlerinin ve değerlendirmelerinin yapılabilmesinde arazi uygunluk özelliklerinin belirlenmesi veya arazi değerlendirme çalışmalarının arttırılması gerekmektedir. Arazi değerlendirme; arazinin belirli bir amaçla kullanıldığı taktirde onun gereksinmelerini karşılama yeteneğinin ve arazinin düşünülen kullanım altında göstereceği performansın belirlemesi işlemidir (FAO, 1976; Cinemre ve Dengiz, 2010). Genellikle arazi değerlendirme metotları, uzman bilgisine dayalı kalitatif ve simülasyon modellerine dayalı kantitatif modeller olarak siniflandırılırlar. 
Kantitatif modeller arazi performansı için oldukça detaylı veri gerektirmektedir. Dolayısıyla, arazi uygunluk veya arazi kalite değerlendirmesi, çok kriterli bir problem olarak görülmelidir. Bir başka ifadeyle, arazi uygunluk çözümlemesi çalışmalarına, birden fazla faktörü içeren bir değerlendirme veya çok kriterli karar verme problemi olarak yaklaşmak daha uygundur (Dengiz ve Sarığlu, 2013). Buna göre, çok kriterli arazi uygunluk değerlendirmeleri matematiksel formüller ile ifade edilmektedir. Parametrik sistemler; farklı kategorik seviyelerde yapilan siniflamaya dayalı hiyerarşik sistemler yerine, tek bir kategorik düzeyi içermektedirler. $\mathrm{Bu}$ sistemle yapılan sinıflamalarda ele alınan her bir faktör, matematiksel modeller içerisinde kullanılarak elde edilen indeks değerlerine göre arazi uygunluk sinıfları belirlenmektedir.

Bir işlemdeki faktörlerin, istenilen seviyelere göre değişen değerlerinin oluşan sonuç üzerindeki etkilerinin araştırılması işlemine deney tasarımı denir (Çömlekci, 2003). Deney tasarımı süreçlerinin, mühendislik çalışmalarının da dahil olduğu birçok uygulama alanı vardır (Williams, 2006; Moreb ve Savsar, 2007; Cestari ve ark., 2008; Jaikumar ve Ramamurthi, 2009; Çoruh ve ark., 2011; Mesci ve Elevli, 2012; Elevli ve Sanyılmaz, 2014). Tam faktöriyel deney tasarımları, seviye sayıs1 birden çok olan, birden fazla sayıdaki faktörün cevap değişkeni üzerindeki etkilerinin ele alındığı deney tasarımı yöntemleridir. Faktöriyel tasarım uygulamalarında her bir faktörün seviyesi diğer faktörlerin seviyeleri ile eşleștirilerek, faktör seviyelerinin alabileceği tüm kombinasyonlar incelenir. Yapılan uygulamada faktör sayısı $k$ olmak üzere faktörlerin iki seviyesinin alınarak çözüm yapıldığ $12^{k}$ faktöriyel deney tasarımı, tam faktör tasarımının özel bir uygulamasidır (George ve ark., 2005; Navidi, 2008). Tam faktöriyel deney tasarımı yöntemi farklı akademik çalışmada kullanılmış olmasına karşın (Şişman, 2014; Şişman ve ark., 2014; Bingol ve ark., 2014; Çoruh ve Gurkan, 2014), arazi ve toprak kaynaklarının tarımsal açıdan uygunluk değerlendirmesine yönelik çalışmalarda hemen hemen hiç uygulanmamıştır.

$\mathrm{Bu}$ çalışmanın amacı, küresel yer belirleme aleti kullanılarak konumsal özellikleri bilinen 889 adet tarım arazilerinden alınan toprak örneğinin, bazı fiziksel ve kimyasal özelliklerine göre Samsun ili tarım arazilerinin kalite durumların parametrik yöntemle saptanması ve bu yöntem içerisinde ele alınan faktörlerin AKI üzerine ne denli etkili olduğunun tam faktöriyel deney tasarımı yöntemi ile belirlenmesidir.

\section{Materyal ve Yöntem}

\section{1. Çalışma alanının tanımı}

Samsun ili; Türkiye'nin Orta Karadeniz bölgesinde Yeşilırmak ve Kızılırmak nehirlerinin Karadeniz'e döküldükleri deltalar arasında yer almaktadır (Şekil 1). Yüz ölçümü $9579 \mathrm{~km}^{2}$ dir. Coğrafi koordinatları, $40^{\circ}$ $50^{\prime}-41^{\circ} 51^{\prime}$ kuzey enlemi ile $37^{\circ} 08^{\prime}$ ve $34^{\circ} 25^{\prime}$ doğu boylamlar arasında yer almaktadır.

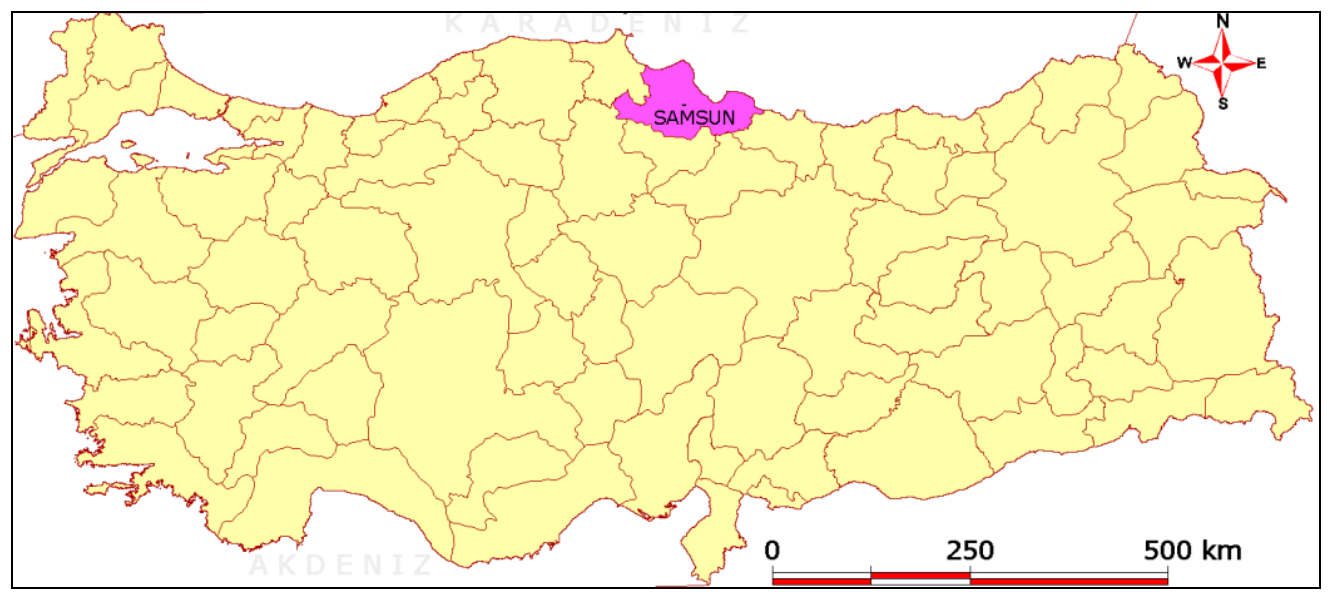

Şekil 1. Samsun ili lokasyon haritası

Samsun ili genellikle 1lıman bir iklime sahiptir. Ancak iklim sahil şeridi ve iç kesimlerde ayrı özellik gösterir. Sahil şeridinde yazların sıcak kışların ılık ve yağışlı geçtiği Karadeniz iklimi özellikleri görülür. İç kesimler ise Akdağ ve Canik Dağlarının etkisinde kalmaktadır. Bu nedenle kışlar soğuk ve kar yağışl1, yazları serin geçmektedir. Çok yıllık ortalamalara göre en soğuk ay Mart $\left(7.2^{\circ} \mathrm{C}\right)$, en sicak ay ise Ağustos $(25.4$ ${ }^{\circ} \mathrm{C}$ ) ayıdır. 2005 yılına ait yıllık ortalama yağış 788.1 $\mathrm{mm}$ ile ülke ortalamasının üzerinde olmuştur. Ortalama nispi nem ise \% 65.2 ile \% 82.5 arasında değişmektedir (Anonim, 2005). Samsun ili yeryüzü şekilleri bakımından üç ayrı özellik gösterir. İlki, güneyindeki dağlık kesim, ikincisi; dağlık kesimle kıyı şeridi arasında kalan yaylalar, üçüncüsü ise, yaylalarla Karadeniz arasında kalan kıyı ovalarıdır. Yeşilırmak ve Kızılırmak akarsularının deltalarında bulunan Bafra ve Çarşamba Ovaları yüksek tarım potansiyeline sahiptir (Candemir ve Özdemir, 2010; Anonim, 2005). İlin deniz 


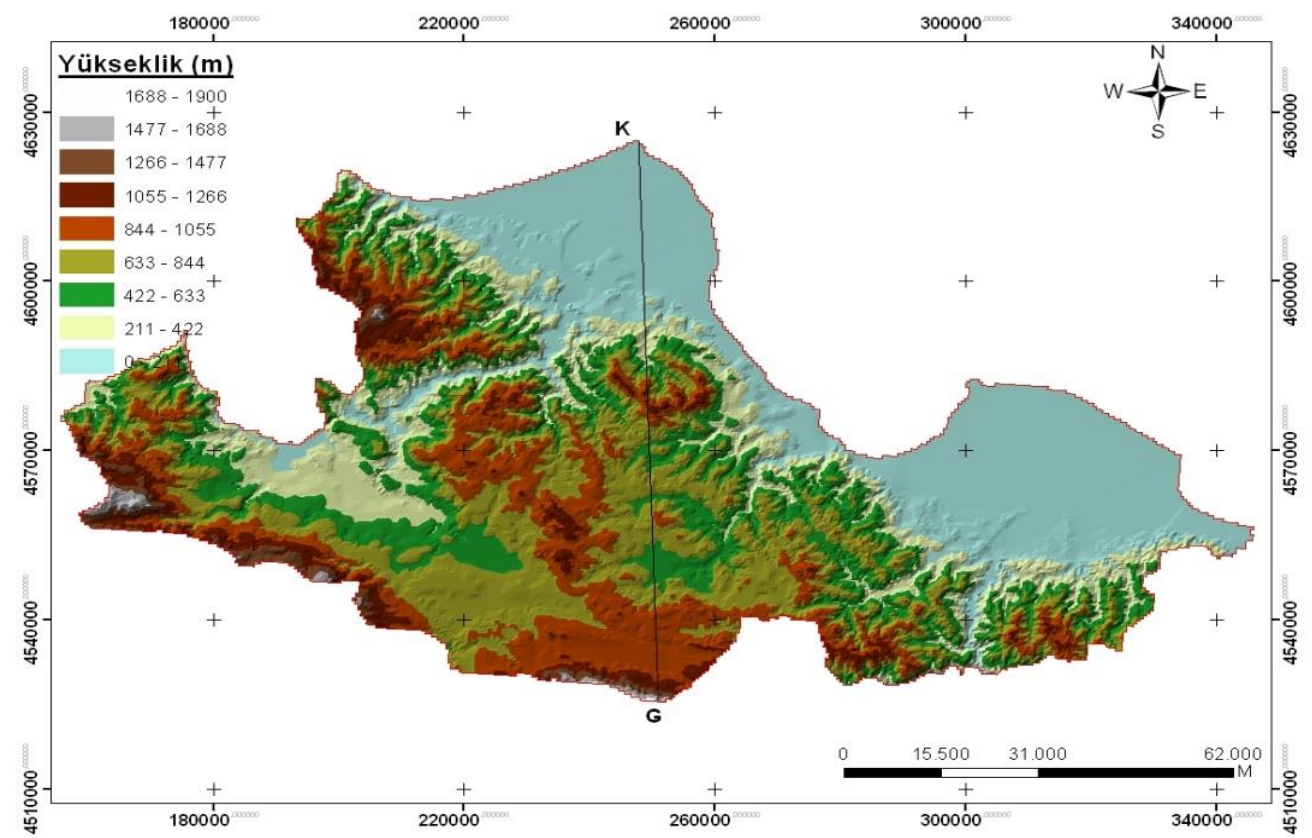

Kuzey- Güney Yönünde Topografik Kesit

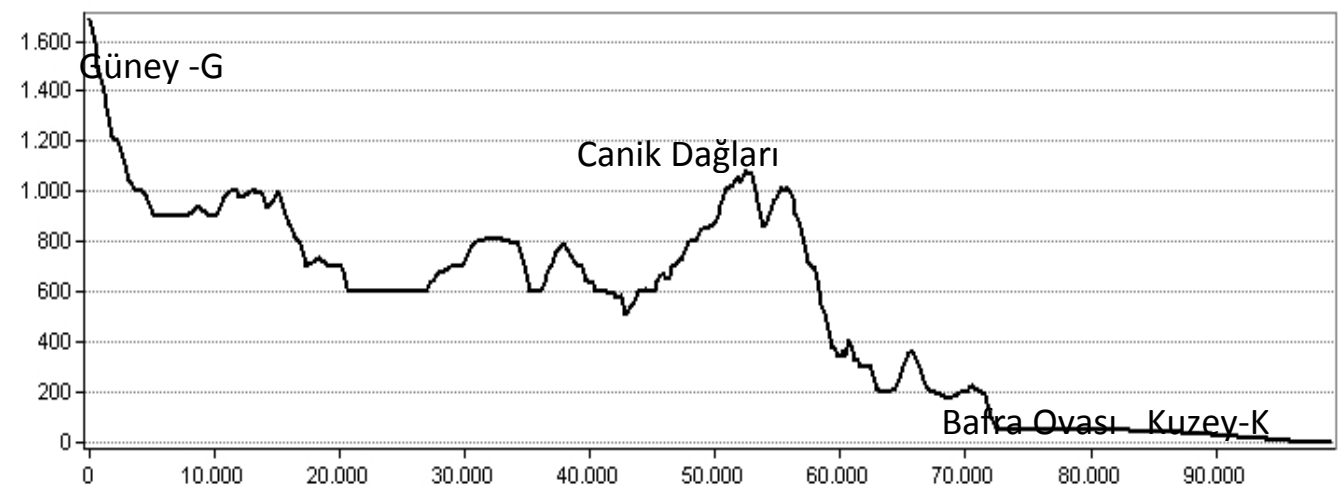

Mesafe $(m)$

Şekil 2. Samsun İli yükseklik dağılım haritası ve topografik kesit

seviyesinden yüksekliği $0-1900 \quad \mathrm{~m} \quad$ arasında değişmektedir (Şekil 2).

\subsection{Yöntem}

\subsubsection{Arazi kalite indeks değerlerin belirlenmesi}

AKI parametrik yaklaşımı, her bir arazi ve toprak karakteristiklerinin sinırlayıcı faktörlerine bağlı olarak değişen düzeylere göre arazi değerlendirmesi işlemidir (Khiddir, 1986; Dengiz, 2002). Arazi ve toprak karakteristikleri olarak fiziksel ve kimyasal olmak üzere iki grup altında i-) toprak derinliği, eğim, bünye, ii-) toprak reaksiyonu $(\mathrm{pH})$, elektriksel iletkenlik (EC) ve organik madde ele alınmış ve her bir faktörün değișen oranları Çizelge 1' de verilmiştir.

AKI değerinin belirlenmesinde kompleks karekök metodu kullanılmıştır. AKI değerlinin hesaplanmasında ele alınan her bir arazi karakteristiğinin değișen seviyedeki oranlarına göre formül (1) ile hesaplamıştır.

$\mathrm{AKI}=\mathrm{R}_{\max } *\left(\sqrt{\frac{A}{100} \times \frac{B}{100} \times \frac{C}{100}}\right) / 100$

AKI: Arazi Kalite İndeksi, Rmax: Ortalama maksimum oran, A, B, C....: Her bir faktörün oransal değeri. AKI değerleri ve uygunluk sinıfları Çizelge 2'de verilmiştir.

2.2.2. Dağılım haritasının oluşturulması enterpolasyon yöntemleri

Çalışma alanında dağılım gösteren tarım arazilerinden grid yöntemine göre her $2.5 \times 2.5 \mathrm{~km}$ 
Çizelge 1. Her bir arazi ve toprak karakteristiklerin değişen seviyelerine göre oranları

\begin{tabular}{|c|c|c|c|c|c|c|c|c|c|c|c|}
\hline \multicolumn{6}{|c|}{ Fiziksel faktörler } & \multicolumn{6}{|c|}{ Kimyasal faktörler } \\
\hline \multicolumn{2}{|c|}{ Derinlik (cm) } & \multicolumn{2}{|c|}{ Eğim (\%) } & \multicolumn{2}{|l|}{ Bünye } & \multicolumn{2}{|l|}{$\mathrm{pH}$} & \multicolumn{2}{|l|}{$\mathrm{EC}$} & \multicolumn{2}{|l|}{$\mathrm{OM}$} \\
\hline Sinif & Oran & Sinıf & Oran & Sinıf & Oran & Sinıf & Oran & Sinif & Oran & Sinif & Oran \\
\hline d: $0-20$ & 30 & A: $0-2$ & 100 & $\begin{array}{l}\text { CL, SCL, } \\
\text { SiCL }\end{array}$ & 100 & $<5$ & 40 & $0-2$ & 100 & $<1$ & 50 \\
\hline $\mathrm{d} 2: 20-50$ & 70 & B: $2-6$ & 95 & $\begin{array}{l}\mathrm{L}, \quad \mathrm{SiL}, \\
\mathrm{Si},<\% 45 \mathrm{C}\end{array}$ & 90 & $5.0-6.0$ & 80 & $2-4$ & 95 & $1-2$ & 80 \\
\hline d3: $50-90$ & 85 & C: $6-12$ & 80 & $\begin{array}{l}>\% 45 \mathrm{C} \\
\mathrm{SC}, \mathrm{SiC}\end{array}$ & 70 & $\begin{array}{l}6.0-6.5 \\
7.5-8.0\end{array}$ & 90 & $4-6$ & 60 & $2-3$ & 95 \\
\hline $\mathrm{d} 4: 90+$ & 100 & $\mathrm{D}:>12$ & 50 & SL, LS, S & 30 & $6.5-7.5$ & 100 & $6-10$ & 20 & $>3$ & 100 \\
\hline
\end{tabular}

OM. Organik madde, EC: Elektiriksel iletkenlik, CL: Kil tın, SCL: Kumlu Kil Tın, SiCL: Siltli Kil Tın, L: Tın, SiL: Siltli Tın, Si: Silt, C: Kil, SiC: Siltli Kil, SL: Kumlu Tin: LS: Tinlı Kum, S: Kum

Çizelge 2. AKI değerleri ve uygunluk sınıflandırmaları (Khiddir, 1986; Dengiz, 2002)

\begin{tabular}{lll}
\hline Tanımlama & Sınıfi & Oran \\
\hline İyi & S1 & $0.75-1.00$ \\
Orta & S2 & $0.50-0.75$ \\
Düşük & S3 & $0.25-0.50$ \\
Tarım dışı & $\mathrm{N}$ & $0.00-0.25$ \\
\hline
\end{tabular}

aralıklarla toplam 889 yüzey $(0-20 \mathrm{~cm})$ toprak örnekleri alınmıştır (Şekil 3). Çalışma alanının eğim durumu 1:25.000 ölçekli topografik haritaların sayısallaştırılması ve oluşturulan sayısal yükselti modeliden yararlanılarak her noktanın eğim sınıfı belirlenmiştir. Her bir noktanın AKI değeri belirlendikten sonra jeoistatistiksel yöntemler kullanılarak alansal dağılımları elde edilmiştir. Gerek topografik haritaların sayısallaştırılmasında gerekse de dağılım haritaların oluşturulmasında ArcGIS 10.2.2v coğrafi bilgi sistemi programı kullanılmıştır.

AKI değerinin alansal dağılımının belirlenmesinde en çok kullanılan enterpolasyon yöntemlerinden IDW, RBF (Spline) deterministik yöntemler ile stokastik yöntemlerden de (temelde Kriging olarak da bilinmektedir) doğal (ordinary), evrensel (universal) ve basit (simple) kriging yöntemleri kullanılmıştır.

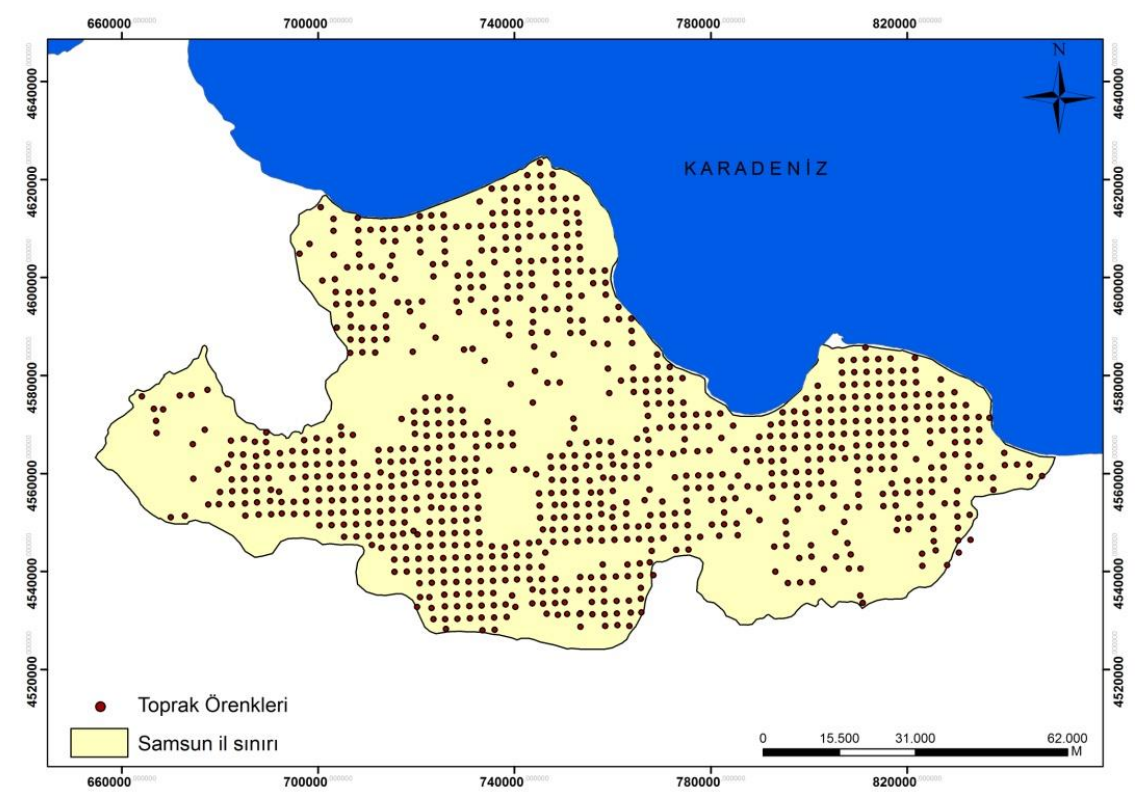

Şekil 3. Çalışma alanının toprak örnekleme deseni

Yöntemlerin karşılaştırılmalarında ölçülen değerler ve tahmin edilen değerler arasındaki ilişkiyi sorgulayabilmek, ölçülen değerlere en yakın sonucu 286 veren başka bir ifade ile yöntemler arasından en uygun olanının seçebilmek için literatürde farklı karşılaştırma yöntemlerinin dikkate alındığı görülmektedir. Genel 
anlamda en yaygın kullanılan yöntemler; hata kareleri ortalamasının karekökü (RMSE), ortalama mutlak hata (MAE), yöntemlerdir. Bu çalışma için RMSE seçilmiş ve jeoistatistiksel çözümde kullanılan 5 yöntem karşılaştırılmıştır. En düşük RMSE değerini veren yöntem, en uygun yöntem olarak değerlendirilmiştir. RMSE'nin hesaplanmasında formül 2 kullanılmıştır.

$R M S E=\sqrt{\frac{\sum\left(z_{i}{ }^{*}-z_{i}\right)^{2}}{n}}$

Eşitlikte; $Z_{i}$ : tahmin edilen değer, $Z_{i^{*}}$ ölçülen değer ve $n$ örnek sayısını ifade etmektedir.

\subsubsection{Deney tasarımı}

Deney tasarımı ile yapılan istatistiksel analizde:

-Faktörler (bağımsız değişkenler); sonuç (bağımlı) değişkeni üzerinde etkisi olduğu düşünülen kontrol edilebilen bağımsız değişkenleri;

-Sonuç değişkeni; ölçülen veya gözlemlenen bağımlı sonuç değerini;

-Seviye; tasarlanan deneyin türüne göre her bir faktörün deneydeki kodlu ya da kodsuz sayısal değerini,

-Ana etki; her bir deney faktörünün sonuç değişkeni üzerindeki diğer faktörlerden bağımsız etkisini;

Etkileşim; iki ya da daha fazla faktörün cevap değişkenine olan etkisini göstermektedir.

$\mathrm{Bu}$ çalışmada AKI değerinde altı faktörün etkisi araştırılmıştır. Ele alınan fiziksel ve kimyasal faktörler, tarımsal yönden toprakların bitkisel üretim açısından doğrudan etkileri dikkate alınmasının yanı sıra diğer toprak özellikleri ile olan yakın ilişkileri göz önüne alınarak seçilmişlerdir. Ayrıca, bu faktörler Dengiz ve Sarıoğlu (2013); Prakash (2003); Bayramin ve Usul (2004) gibi birçok arazi kalite modelleme ve bitkisel uygunluk sınıflama çalışmalarında da yer verilmiş olmaları nedeniyle model içerisine dahil edilmişlerdir. AKI belirlenmesinde $2^{k}$ faktöriyel tasarımı kullanılmıştır. Yapılan deney tasarımında, eğim, bünye, $\mathrm{pH}$, EC ve organik maddenin faktör, AKI değerinin sonuç değişkeni olarak alınmıştır. AKI hesaplamasında EC faktörü 889 toprak örneğinde 0.257 ile $2.129 \mathrm{dSm}^{-1}$ arasında yer alması bitki gelişiminde olumsuz etki göstermemesi ( $4 \mathrm{dSm}^{-1}$ den az olması) nedeniyle tüm örneklerin aldı $\breve{g} 1$ oran 1.0 'dir. Benzer şekilde $\mathrm{pH}$ değerlerinin de 5.51-7.80 arasında yer alması nedeniyle oran değerleri 0.80-1.0 arasında olduğu belirlenmiştir. Deneyin tasarımı aşamasında seçilen faktörlerden EC ve pH uygulama bölgesinde değişkenlik göstermediği tespit edilmiş ve bu faktör deney tasarımı uygulamasına dahil edilmemiştir. Yani bu iki faktör iki seviyeli tam faktöriyel deney tasarımından çıkarılarak $2^{4}$ faktöriyel tasarımı yapılmıştır. Yapılan çalışma sonucunda tüm faktörlerin ana etkilerinin, bazı faktörlerin etkileşimlerinin AKI üzerinde etkili olduğu görülmüştür. Analiz sonuçlardan AKI ve seçilen faktörler arasında $y=f(x)$ şeklinde yazılan bir regresyon eşitliği elde edilmiştir. Çizelge 3'de uygulamaya dahil edilebilen deney faktörleri ve seviyeleri gösterilmiştir.

Çizelge 3. Deney faktörleri ve seviyeleri

\begin{tabular}{llll}
\hline Faktör & Sembol & $\begin{array}{l}\text { Düşük } \\
\text { Seviye (-1) }\end{array}$ & $\begin{array}{l}\text { Yüksek } \\
\text { Seviye }(+1)\end{array}$ \\
\hline Derinlik & $A$ & 0.3 & 1.0 \\
Eğim & $B$ & 0.5 & 1.0 \\
Bünye & $C$ & 0.3 & 1.0 \\
OM & $D$ & 0.8 & 1.0
\end{tabular}

Dört faktöre göre tasarlanan $2^{4}=16$ deney 2 tekrarlı şekilde yapıldığında elde edilen sonuçlar Çizelge 4 'de gösterilmiştir.

Çizelge 4. Tasarım matrisi

\begin{tabular}{|c|c|c|c|c|c|c|}
\hline \multirow{2}{*}{$\begin{array}{l}\text { Deney } \\
\text { No }\end{array}$} & \multirow{2}{*}{$\begin{array}{l}\text { Derinlik } \\
\text { (A) }\end{array}$} & \multirow{2}{*}{$\begin{array}{l}\text { Eğim } \\
\text { (B) }\end{array}$} & \multirow{2}{*}{$\begin{array}{l}\text { Bünye } \\
\text { (C) }\end{array}$} & \multirow{2}{*}{$\begin{array}{l}\text { OM } \\
\text { (D) }\end{array}$} & I. Deneme & II. Deneme \\
\hline & & & & & \multicolumn{2}{|c|}{ Arazi Kalite İndeksi } \\
\hline 1 & 0.3 & 0.5 & 0.3 & 0.8 & 0.12 & 0.12 \\
\hline 2 & 1.0 & 0.5 & 0.3 & 0.8 & 0.25 & 0.25 \\
\hline 3 & 0.3 & 1.0 & 0.3 & 0.8 & 0.18 & 0.18 \\
\hline 4 & 1.0 & 1.0 & 0.3 & 0.8 & 0.39 & 0.39 \\
\hline 5 & 0.3 & 0.5 & 1.0 & 0.8 & 0.25 & 0.27 \\
\hline 6 & 1.0 & 0.5 & 1.0 & 0.8 & 0.56 & 0.56 \\
\hline 7 & 0.3 & 1.0 & 1.0 & 0.8 & 0.39 & 0.39 \\
\hline 8 & 1.0 & 1.0 & 1.0 & 0.8 & 0.86 & 0.75 \\
\hline 9 & 0.3 & 0.5 & 0.3 & 1.0 & 0.13 & 0.13 \\
\hline 10 & 1.0 & 0.5 & 0.3 & 1.0 & 0.31 & 0.29 \\
\hline 11 & 0.3 & 1.0 & 0.3 & 1.0 & 0.21 & 0.21 \\
\hline 12 & 1.0 & 1.0 & 0.3 & 1.0 & 0.42 & 0.39 \\
\hline 13 & 0.3 & 0.5 & 1.0 & 1.0 & 0.42 & 0.39 \\
\hline 14 & 1.0 & 0.5 & 1.0 & 1.0 & 0.65 & 0.56 \\
\hline 15 & 0.3 & 1.0 & 1.0 & 1.0 & 0.47 & 0.43 \\
\hline 16 & 1.0 & 1.0 & 1.0 & 1.0 & 1.00 & 0.93 \\
\hline
\end{tabular}


Faktörlerin düşük (-1) ve yüksek (+1) seviyeleri için yapılan deneylerden elde edilen AKI değerlerine ait grafik Şekil 4'de göstermektedir. Faktör sayısı 4 olduğu için iki küpün köşe noktaları bu değerleri temsil etmeye yeterli olmuştur. Veri analizi aşamasında Minitab 16 istatistiksel yazılımından yararlanılmıştır.

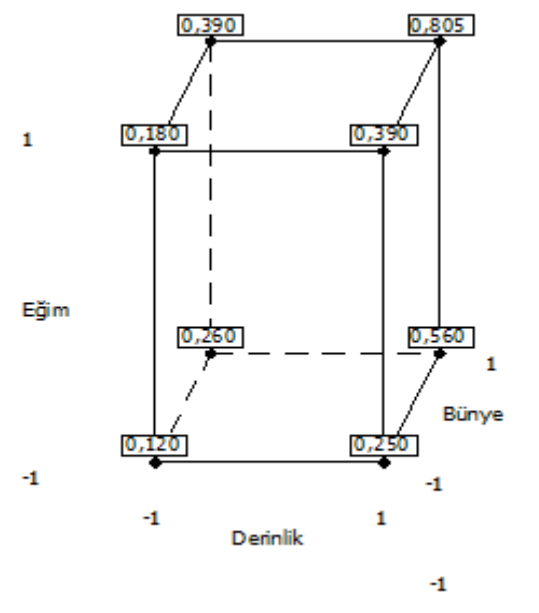

OM

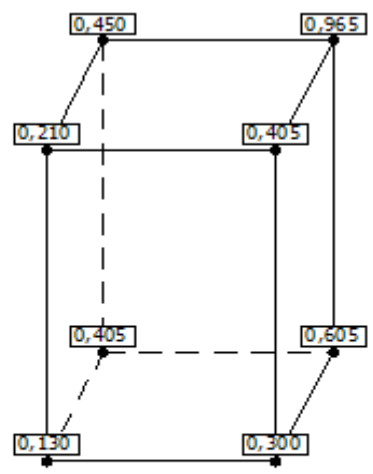

Şekil 4. AKI için yapılan deneylerin küp grafiği

\section{Bulgular ve Tartış̧a}

\subsection{Arazi kalite indeks dağılımı}

Samsun ili AKI değerlerinin alansal analizi kapsamında 5 farklı enterpolasyon yöntemi kullanılmıştır. Hangi dağılımın en doğru olduğunun belirlenmesi amacıyla her bir yöntem için çapraz doğrulama yapılmış ve her bir yöntemin RMSE değeri belirlenmiştir. Yöntemlere ait RMSE değerleri Çizelge 5'de verilmiştir. Çizelgede görüleceği üzere en küçük RMSE değerini veren yöntemin IDW-3 yöntemi olduğu belirlenmiştir.

Çizelge 5. Enterpolasyon yöntemlerine göre çapraz doğrulama sonuçları

\begin{tabular}{lll}
\hline $\begin{array}{l}\text { Enterpolasyon } \\
\text { yöntemleri }\end{array}$ & Pover/Semivariogram & RMSE \\
\hline & 1 & 0.1596 \\
IDW & 2 & 0.1599 \\
& 3 & $\mathbf{0 . 1 1 0 7}$ \\
RBF & STP & 0.1595 \\
Ordinary Kriging & Exponential & 0.1589 \\
Universal Kriging & Exponential & 0.1589 \\
Simple Kriging & Exponential & 0.1578 \\
\hline
\end{tabular}

IDW-3 enterpolasyon yöntemi kullanılarak AKI dağılım oranları Çizelge 6 ve dağılım haritası Şekil 5 de verilmiștir. Toplam alanın \%67'lik gibi büyük bir kısmı orta uygunluk sınıfında iken, toplam alanın yaklaşık \%24'lük bölümü ise tarımsal kalite açısından hiç uygun olmayan alanlar sınıfinda bulunduğu ve bu alanlarında özellikle Samsun ilinin eğimi fazla ve toprak derinliği az olan kesimlerinde yer aldığı saptanmıştır. Tarımsal kullanım açısından en uygun alanların büyük bir çoğunluğunun ise Bafra ve Çarşamba Ovaları içerisinde dağılım göstermiştir.

Çizelge 6. AKI sınıflarının alansal ve oransal dağılımları

\begin{tabular}{llcr}
\hline AKI & \multicolumn{3}{c}{ Alan } \\
\hline Sinıf & Aralı & Ha & $\%$ \\
\hline N & $0.00-0.25$ & 1651.1 & 0.17 \\
S3 & $0.25-0.50$ & 230185.1 & 24.03 \\
S2 & $0.50-0.75$ & 643460.0 & 67.17 \\
S1 & $0.75-1.00$ & 82602.9 & 8.62 \\
\hline \multicolumn{2}{l}{ Toplam } & 957899.1 & 100.00 \\
\hline
\end{tabular}

\subsection{Deney tasarım sonuçları}

Verilerin istatistiksel analizi için ilk olarak, varyans analizi (ANOVA) yapılarak ana etkilerin ve etkileşimlerin sıfira eşit olduğunu varsayan sıfir hipotezi, F testi kullanılarak test edilmiştir. Çizelge 7' de yer alan 0.05 'den küçük olan $p<0.05$ değerleri, tüm etkilerin ve etkileşimlerin $\% 5$ anlamlılık düzeyinde sıfıra eşit olmadığını göstermektedir. Bir başka ifadeyle, ANOVA'ya göre $\mathrm{A}, \mathrm{B}, \mathrm{C}$ ve $\mathrm{D}$ faktörleri ve $\mathrm{A} * \mathrm{~B}, \mathrm{~A}^{*} \mathrm{C}$, $B * C, C^{*} D, A * B * C, A * B^{*} C^{*} D$ etkileşimi AKI üzerinde istatistiksel olarak etkili parametrelerdir 


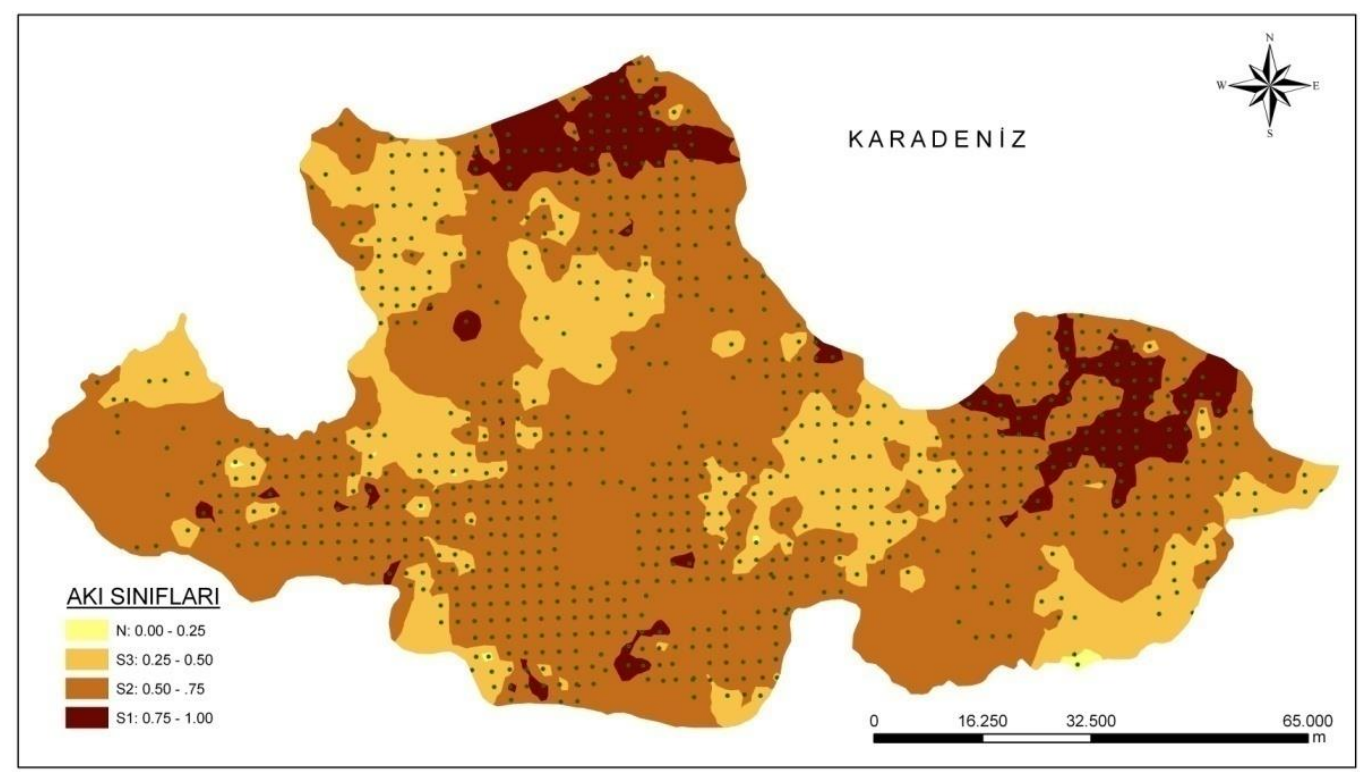

Şekil 5. AKI sınıflarına ait dağılım haritası

Çizelge 7. Varyans analizi sonuçları

\begin{tabular}{llllll}
\hline Değişim kaynağı & S. D. & Kareler toplamı & Kareler ortalaması & F & P \\
\hline Ana etkiler & 4 & 1.5260 & 0.3815 & 416.650 & 0.000 \\
\hline A & 1 & 0.5698 & 0.5698 & 622.280 & 0.000 \\
B & 1 & 0.1697 & 0.1697 & 185.290 & 0.000 \\
C & 1 & 0.7534 & 0.7534 & 822.800 & 0.000 \\
D & 1 & 0.0332 & 0.0332 & 36.210 & 0.000 \\
\hline İki yönlü etkileşimler & 6 & 0.1327 & 0.0221 & 24.160 & 0.000 \\
\hline A*B & 1 & 0.0358 & 0.0358 & 39.080 & 0.000 \\
A*C & 1 & 0.0657 & 0.0657 & 71.760 & 0.000 \\
A*D & 1 & 0.0001 & 0.0001 & 0.090 & 0.774 \\
B*C & 1 & 0.0195 & 0.0195 & 21.300 & 0.000 \\
B*D & 1 & 0.0000 & 0.0000 & 0.030 & 0.863 \\
C*D & 1 & 0.0116 & 0.0116 & 12.700 & 0.003 \\
\hline Üç yönlü etkileşimler & 4 & 0.0162 & 0.0040 & 4.410 & 0.014 \\
\hline A*B*C & 1 & 0.0132 & 0.0132 & 14.420 & 0.002 \\
A*B*D & 1 & 0.0026 & 0.0026 & 2.870 & 0.110 \\
A*C*D & 1 & 0.0001 & 0.0001 & 0.090 & 0.774 \\
B*C*D & 1 & 0.0003 & 0.0003 & 0.280 & 0.606 \\
\hline Dört yönlü etkileşimler & 1 & 0.0081 & 0.0081 & 8.880 & 0.009 \\
\hline A*B*C*D & 1 & 0.0081 & 0.0081 & 8.880 & 0.009 \\
Hata & 16 & 0.01465 & 0.000916 & & \\
Genel & 31 & 1.69762 & & & \\
\hline S.D $*$ Serben & & & &
\end{tabular}

S.D.=Serbestlik Derecesi A: Derinlik B: Eğim C: Bünye D: Organik Madde.

Faktörlerin standartlaştırılmış ana ve etkileşim etkilerinin sonuç değişkeni üzerindeki anlamlılığını ve etki seviyesi pareto ve yarı normal etkiler grafiği ile gösterilir. Ana ve etkileşim etkilerinden paretoya göre çizginin üzerinde kalanlar; yarı normal etkiler grafiğgine göre ise çizgiden uzak olanlar istatistiksel olarak anlamlıdır. $\mathrm{Bu}$ çalışma için oluşturulan Şekil 6'e bakıldığında yine ana etkilerde $\mathrm{A}, \mathrm{B}, \mathrm{C}$ ve $\mathrm{D}$ faktörleri ve etkileşimde $\mathrm{A} * \mathrm{~B}, \mathrm{~A} * \mathrm{C}, \mathrm{B} * \mathrm{C}, \mathrm{C} * \mathrm{D}, \mathrm{A} * \mathrm{~B} * \mathrm{C}$, $\mathrm{A} * \mathrm{~B} * \mathrm{C} * \mathrm{D}$ ’nin anlamlı olduğu görülmektedir. 

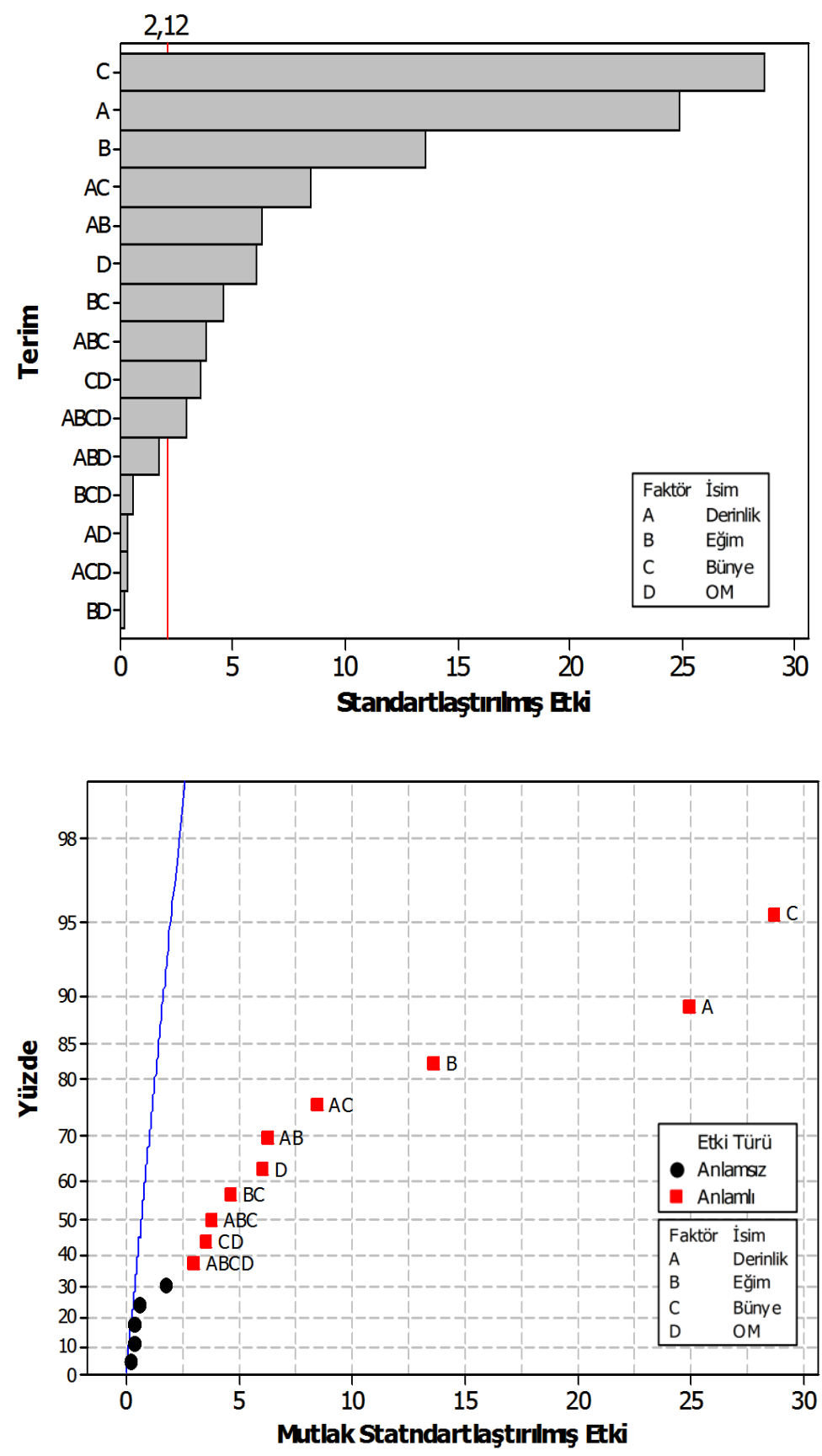

Şekil 6. Pareto ve Yarı Normal Etkiler Grafiği

Çizelge 7'de verilen analiz sonuçlarına göre sadece AKI üzerinde etkili olan terimler modelde çıkarılarak bu analiz tekrarlanmıştır. Çizelge 8'de AKI için etkili terimler için etkiler ve katsayıları t-testi ile istatistiksel olarak elde edilmişlerdir.

Çizelge 8'de verilen faktör etkilerinin mutlak değeri, ilgili deneysel faktörün cevap değişkeni üzerindeki oransal etkisini göstermektedir. C faktörünün etkisinin mutlak değerinin en yüksek oluşu, bu faktörün AKI üzerinde en etkili bağımsız değişken olduğunu göstermektedir. Faktörlerin AKI üzerindeki etkisine göre sıralaması en önemliden başlamak üzere C, A, B,
$\mathrm{A} * \mathrm{C}, \quad \mathrm{A} * \mathrm{~B}, \quad \mathrm{~B} * \mathrm{C}, \quad \mathrm{A} * \mathrm{~B} * \mathrm{C}, \quad \mathrm{C} * \mathrm{D} \quad$ ve $\quad \mathrm{A} * \mathrm{~B} * \mathrm{C} * \mathrm{D}$ şeklindedir.

$\mathrm{R}^{2}$ değerleri cevap değişkeninin ne kadarının modeldeki terimler tarafından açıklandığını göstermekte olup, varyans analizi tablosundaki kareler toplamından yararlanılarak bulunmaktadır. Analiz sonuçlarına göre AKI değişkenliğin yaklaşık olarak \%98.96'sı $\left(\mathrm{R}^{2}=0.99\right)$ deney tasarımında dâhil edilen faktörlerden kaynaklanmaktadır.

Çizelge 8'de verilen katsayı, herhangi bir etkinin bir birim arttı̆̆ında çıktı üzerinde yaratacağı etkiyi göstermektedir. Faktörlerin sonuç değiş̧keni üzerindeki 
Çizelge 8. AKI için tahmin edilen etkiler ve katsayılar

\begin{tabular}{lllcll}
\hline Terim & Etki & Katsayı & $\begin{array}{c}\text { Katsayını Std. } \\
\text { hatas } 1\end{array}$ & $\mathrm{~T}$ & $\mathrm{P}$ \\
\hline Sabit & & 0.4016 & 0.0051 & 78.21 & 0.000 \\
$\mathrm{~A}$ & 0.2669 & 0.1334 & 0.0051 & 25.99 & 0.000 \\
$\mathrm{~B}$ & 0.1456 & 0.0728 & 0.0051 & 14.18 & 0.000 \\
$\mathrm{C}$ & 0.3069 & 0.1534 & 0.0051 & 29.88 & 0.000 \\
$\mathrm{D}$ & 0.0644 & 0.0322 & 0.0051 & 6.27 & 0.000 \\
$\mathrm{~A} * \mathrm{~B}$ & 0.0669 & 0.0334 & 0.0051 & 6.51 & 0.000 \\
$\mathrm{~A} * \mathrm{C}$ & 0.0906 & 0.0453 & 0.0051 & 8.83 & 0.000 \\
$\mathrm{~B} * \mathrm{C}$ & 0.0494 & 0.0247 & 0.0051 & 4.81 & 0.001 \\
$\mathrm{C} * \mathrm{D}$ & 0.0381 & 0.0191 & 0.0051 & 3.71 & 0.001 \\
$\mathrm{~A} * \mathrm{~B} * \mathrm{C}$ & 0.0406 & 0.0203 & 0.0051 & 3.96 & 0.001 \\
$\mathrm{~A} * \mathrm{~B} * \mathrm{C} * \mathrm{D}$ & 0.0319 & 0.0159 & 0.0051 & 3.10 & 0.005 \\
\hline
\end{tabular}

$\mathrm{S}=0.0290 \mathrm{R}^{2}=98.96 \% \mathrm{R}^{2}$ (tah.) $=97.58 \% \mathrm{R}^{2}$ (düz. $)=98.46 \%$

etkileri için istatistiksel analizde elde edilen katsayı değerleri kullanılarak bir regresyon eşitliği yazılabilir.
Çizelge 8'e göre AKI için yazılan regresyon eşitliği formül 3' den aşağıdaki şekilde elde edilir.

$$
\begin{aligned}
\mathrm{Y}= & 0,4016+0,1334 * \mathrm{~A}+0,0728 * \mathrm{~B}+0,1534 * \mathrm{C}+0,0322 * \mathrm{D}+0,0334 * \mathrm{~A} * \mathrm{~B}+0,0453 * \mathrm{~A} * \mathrm{C}+ \\
& 0,0247 * \mathrm{~B} * \mathrm{C}+0,0191 * \mathrm{C} * \mathrm{D}+0,0203 * \mathrm{~A} * \mathrm{~B} * \mathrm{C}+0,0159 * \mathrm{~A} * \mathrm{~B} * \mathrm{C} * \mathrm{D}
\end{aligned}
$$

Şekil 7'de faktörlerin ana etki grafikleri görülmektedir. Bir faktörün ana etkisi; faktör yüksek seviyede ve düşük seviyede iken hesaplanan ortalama cevap değişkenleri arasındaki farktır. Ana etki grafiğinde, bir faktörün seviye değişimlerinin cevap değişkeni üzerinde yaratacağı fark ne kadar büyük ise, seviyeleri birleştiren çizgi o kadar dik olacaktır. $\mathrm{Bu}$ açıklama 1şığında Bünye (C) ve Derinlik (A) faktörlerinin diğer faktörlere göre oransal olarak daha etkili bir faktör olduğu açıkça anlaşılmaktadır.

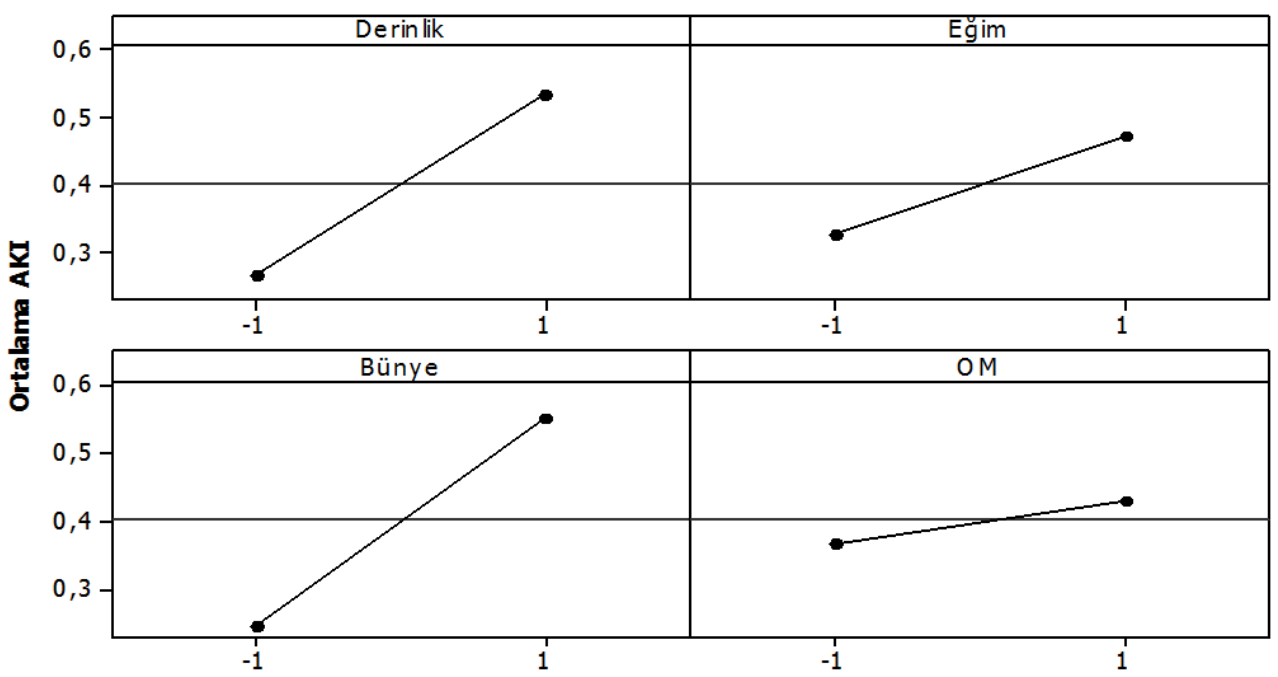

Şekil 7. Ana etkiler grafiğgi 
Deney tasarımı, artıkların (residual) bağımsız ve normal dağıldığ varsayımın geçerliliğini göstermek üzere Şekil 8'de

\section{Normal Dağılım Garfiği}

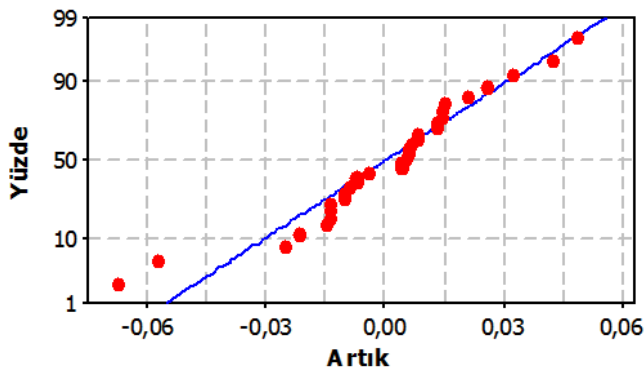

Histogram

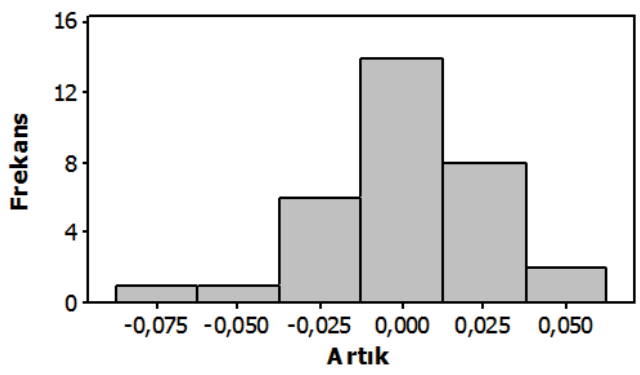

verilen artık grafiklerinden yararlanılmıştır. $\mathrm{Bu}$ varsayımla ilgili bir sorun olmadığı için elde edilen modelin geçerli bir model olduğu sonucuna ulaşılmıştır.

Artık-Uydurulan Değer Grafiği

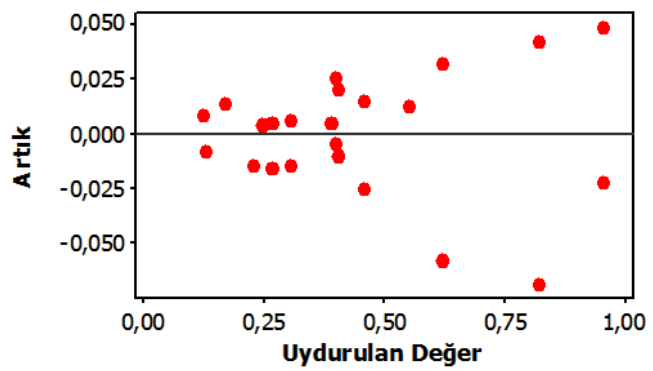

Artık Değerler-Gözlem Sırası Grafiği

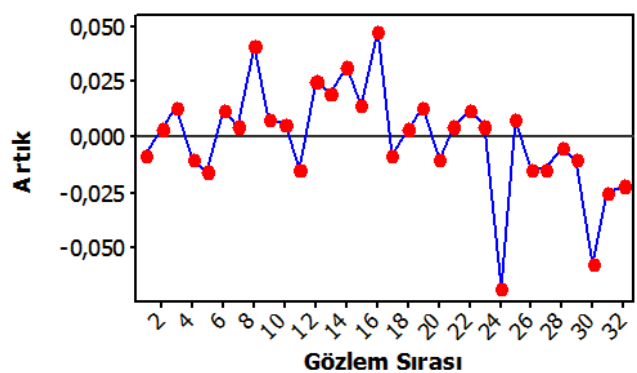

Şekil 8. Artıkların grafiksel analizi

\section{Sonuc}

$\mathrm{Bu}$ çalışma kapsamında arazilerin tarımsal açıdan uygunluklarının belirlenmesine yönelik parametrik bir yaklaşım olan arazi kalite indeks modeli, jeoistatistik gibi model ve tekniklerden yararlanılarak belirlenmesinin yanı sira ilk kez toprak ve arazi uygunluk çalışmalarında modelde ele alınan kriterlerin deney tasarımı ile irdelenmesi yapılmıştır.

Tarımsal amaçlı arazi kalite çalışmalarında gerek parametrik gerekse hiyerarşik yaklaşımlarda arazi ve toprağa yönelik fiziksel, kimyasal ve verimlilik gibi özellikler içerisinde çok fazla kriter kullanılmaktadır. Özellikle güncel toprak haritaları olmayan geniş alanlarda noktasal örneklemeler ile arazi ve toprak özelliklerin tarımsal açıdan kalite özelliklerinin belirlenmesinde, gerek örnekleme sayısın çok fazla olması, gerekse de ele alınan kriter sayısının fazla olması nedeniyle çok fazla iş gücü, maliyet ve zaman kaybına neden olmaktadır. Konumsal özellikleri bilinen 889 adet toprak örneği alınan Samsun ili tarım arazilerinin kalite özelliklerinin belirlenmesinde deney tasarımı yaklaşımı ile benzer alanlar için daha az sayıda örnekleme ve kriterlerle benzer sonuçların elde edilebileceği görülmüştür.

Deney tasarımı, bir sürecin sonuç değişkeni üzerinde girdi faktörlerinin ne denli etkili olduğunun araştırılması amacıyla kullanılan bir teknik olup, süreç sorunlarının çözümü ve süreç iyileştirme çalışmalarında yaygın olarak kullanılmaktadır. Bu çalışmada AKI belirleme çalışmalarında faktörlerin etkilerini belirlemek amacıyla $2^{4}$ faktöriyel deney tasarımından yararlanılmıştır. Çalışma sonucunda seçilen faktörlerin ana etkilerinin, ayrıca ikili, üçlü ve dörtlü etkilerin AKI üzerinde etkili olduğu tespit edilmiştir. $\mathrm{Bu}$ çalışma sonucunda uygulama alanı için seçilen faktörlere göre bir AKI regresyon eşitliği elde edilmiştir. Bu eşitlikle faktörlerin diğer seviyeleri için AKI değerinin tahmin edilmesi söz konusudur. Bu çalışmanın en önemli sonuçlarından biri de kullanılan deney sayısıdır. $2^{4}$ deneyin 2 tekrarlı verisi yani toplam 32 deney kullanılarak 889 noktalı Samsun AKI çalışması sonuçları \%98.96 oranında temsil edilmiştir.

\section{Kaynaklar}

Anonim, 2005. Samsun İl Çevre Durum Raporu. Samsun İl Cevre ve Orman Müdürlüğü Yayını. No: 22.

Bingol, D., Saraydın, D., Ozbay, D.S., 2014. Full Factorial Design Approach to $\mathrm{Hg}(\mathrm{II})$ Adsorption onto Hydrogels, Arab J Sci Eng, DOI: 10.1007/s13369-0140,8484-x.

Bayramin, I., Usul, M., 2004. Physical land evaluation of Salihli right coast irrigation area. International Soil Congress on Natural Resource Management for Sustainable Development, Erzurum, Turkey.

Candemir, F., Özdemir, N., 2010. Samsun İli arazi varliği ve toprak sorunlari. Anadolu Tarım Bilim. Derg., 25(3): 223229.

Cestari, A.R., Vieira, E.F.S., Mota, J.A., 2008. The removal of an ionic red dye from aqueous solutions using chitosan 
beads-The role of experimental factors on adsorption using a full factorial design. Journal of Hazardous Materials, 160: 337-343.

Cinemre, H.A., Dengiz, O., 2010. Arazi Kullanım Planlaması. Ondokuz Mayıs Üniversitesi Ziraat Fakültesi Ders Kitabı No: 64, Samsun.

Çömlekçi, N., 2003. Deney Tasarımı İlke ve Teknikleri, Alfa Yayınları, İstanbul, 468.

Coruh, S., Elevli, S., Senel, G., Ergun, O.N., 2011. Adsorption of silver from aqueous solution onto fly ash and phosphogypsum using full factorial design. Environ. Prog. Sustain. Energy, 30(4): 609-619.

Coruh, S., Gurkan, H.E. 2014. Adsorption of neutral red from aqueous solutions using waste foundry sand: Full Factorial Design Analysis Environmental Progress \& Sustainable Energy. 33(4): 1086-1095.

Dengiz, O. 2002. Ankara-Gölbaşı İlçesi ve yakın çevresinde yayilim gösteren arazilerin kalite durumlarının belirlenmesinde parametrik metot yaklaşımı. Selçuk Üniversitesi Ziraat Fakültesi Tarım Bilimleri Dergisi, 16(30): 59-69.

Dengiz, O., Sarığlu, F.E., 2013. Parametric approach with linear combination technique in land evaluation studies. Journal of Agricultural Sciences, 19 (2): 101-112.

Elevli, S., Sany1lmaz, M., 2014. Experimental design of fuse link with ceramic alloy: Cracking problem. Hemijska Industrija, 68(1): 35-41.

FAO, 1976. A Framework for land evaluation: Soils Bulletin 32, Food and Agriculture Organization of the United Nations, Rome, Italy.

George, M.L., Rowlands, D., Price, M., Maxey, J., 2005. Lean
Six Sigma Pocket Toolbook, McGraw-Hill, New York, 282.

Jaikumar, V., Ramamurthi, V., 2009. Statistical analysis and optimization of acid dye biosorption by brewery waste biomass using response surface methodology. Mod. Appl. Sci., 3(4): 71-86.

Khiddir, S. M. 1986. A ststistical approach in the use of parametric systems to the FAO framework for land evaluation. Ph.D Thesis University Gent, Belgium.

Mesci, B., Elevli, S., 2012. Recycling of chromite waste for concrete: Full factorial design approach. Int. J. Environ. Res. 6(1): 145-150.

Moreb, A.A., Savsar, M., 2007. Minimizing defects in turfing process using full factorial design. WSEAS Trans. Business Econ., 3(4): 54-57.

Navidi, W., 2008. Statistics for Engineers and Scientist, McGraw-Hill Companies, Inc., NewYork, 928.

Prakash, T.N., 2003. Land Suitability Analysis for Agricultural Crops: A Fuzzy Multicriteria Decision Making Approach. International Institute for GeoInfrormation Science and earth Obsevation Enschede, The Neterherland, 51.

Şişman, Y., 2014. Full Factorial Design Approach for Coordinate Transformation. Arab J Sci Eng., 39: 227-235.

Şişman, Y., Elevli, E., Şişman, A., 2014. A statistical analysis of GPS positioning using experimental design. Acta Geod Geophys, 49: 343-355.

Williams, P.H., 2006. Designing Experiments for the Modern Micro Industries, 58-63. 